\section{FORMULASI PATCH ANTIPIRETIK YANG MENGANDUNG EKSTRAK COCOR BEBEK (Kalanchoe pinnata)} \\ Antipyretic Patch Formulation Containing Extract (Kalanchoe Pinnata) \\ Santi Sinala*, Ismail Ibrahim, Sisilia Teresia Rosmala Dewi \\ Poltekkes Kemenkes Makassar \\ *Koresponden Email : santisinala@poltekkes-mks.ac.id
}

Mfluses

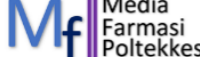

DOI: https://doi.org/10.32382/mf.v17i1.1972

\begin{abstract}
Fever in children requires special treatments coupled with practical use of drugs. Therefore, this research aims to formulate antipyretic patch preparations containing Kalanchoe pinnata plant extracts. The plant was first extracted using the maceration method, meanwhile, the patch formulation was made with 3 different concentrations of $\mathrm{Na} \mathrm{CMC}$ base. Thereafter, the extract was then added to the base patch. The three formulas were tested for the characteristics, namely organoleptic, weight uniformity, thickness, percentage of water loss, $\mathrm{pH}$, and folding resistance. The results showed that the three formulas have the same organoleptic color, namely green, F1 is not homogeneous, while F2 and F3 are homogeneous. Moreover, the three formulas met the weight uniformity requirements, while in the thickness test, F3 is thicker compared to F2 and F1. F3 has a water content greater than F2 and F1, meanwhile, the three formulas have a $\mathrm{pH}$ of 6 and folding resistance $>300$ times. Based on the results, Formula 2 (F2) has better physical stability compared to F1 and F3.
\end{abstract}

Keywords: Kalanchoe pinnata, patch, antipyretic

\title{
ABSTRAK
}

Demam pada anak membutuhkan penanganan khusus dimana penggunaan obat harus lebih praktis. Penelitian ini akan memformulasi sediaan patch bberbahadan dasar tanaman cocor bebek. Penelitian ini bertujuan untuk memformulasi sediaan patch antipretik yang mengandung ekstrak tanaman cocor bebek. Tanaman cocor bebek terlebih dahulu diekstraksi menggunakan metode maserasi untuk menghasilkan ekstrak. Formulasi patch dibuat dengan 3 konsentrasi basis Na CMC yang berbeda. Ekstrak kemudian ditambahkan ke dalam basis patch. Ketiga formula diuji karakteristiknya meliputi uji organoleptis, keseragaman bobot, uji ketebalan, persentase kehilangan air, uji pH dan uji daya tahan lipat. Hasil pengujian diperoleh dimana ketiga formula memiliki organoleptis warna yang sama yaitu hijau, F1 tidak homogen, sedangkan F2 dan F3 homogen. Pada uji keseragaman bobot, ketiga formula memenuhi syarat keseragaman bobot. Pada uji ketebalan, F3 lebih tebal dibandingkan dari F2 dan F1. F3 memiliki kadar air yang lebih besar dibandingkan dengan F2 dan F1. Pada uji pH, ketiga formula memiliki pH 6 dan memiliki kemampuan bertahan meski telah dilipat $>300$ kali. Formula 2 (F2) memiliki kestabilan fisik yang lebih baik disbanding dari F1 dan F3.

Kata Kunci : Cocor bebek, patch, antipiretik

\section{PENDAHULUAN}

Demam merupakan salah satu keadaan kesehatan yang terganggu dimana sering dijumpai pada anak. Demam adalah keadaan temperatur tubuh berada di atas temperature batas normal, yaitu temperatur tubuh di atas 38 ${ }^{\circ} \mathrm{C}$. (Tortora, 1990). Keadaan demam pada anak yang sering terjadi dan muncul tiba-tiba membuat dimana seorang ibu harus selalu menyiapkan penanganan demam di rumah misalnya mempersiapkan obat penurun deman (antipiretik) di kotak obat.

Pengobatan demam pada anak biasanya menghadapi kesulitan tersendiri dimana karena tidak semua pasien anak dapat dan suka minum obat, sehingga diperlukan penggunaan obat yang lebih praktis. Pengunaan obat menggunakan jalur transdermal merupakan salah satu aplikasi yang 
efektif dan praktis. Salah satu penggunaan jalur transdermal adalah penggunaan sediaan patch. Menyesuaikan dengan kondisi anak, maka para orang tua kebanyakan lebih memilih menggunakan sediaan pacth untuk mengobati demam dengan alasan kepraktisan, kenyamanan dan kemudahan pada penggunaannya pada anak. Berkembangnya pengetahuan dan teknologi, bidang Farmasi juga membuat terobosan baru yaitu membuat sediaan seperti kompres pada dahi namun lebih efisien dan efektif. Hal ini dapat dilihat pada sediaan Bye-Bye Fever $^{\circledR}$, dimana sediaan ini diletakkan di dahi.

Patch transdermal merupakan sediaan drug delivery systems yang memiliki perekat denga sifat yang lunak, dimana mengandung senyawa obat, yang nantinya akan melepaskan zat aktif dalam dosis tertentu melalui kulit. Melalui bentuk sediaan patch transdermal jumlah pelepasan obat yang diinginkan dapat dikendalikan, durasi penghantaran aktivitas terapeutik dari obat, dan target penghantaran obat ke jaringan yang dikehendaki. Tujuan dari pemberian obat secara transdermal adalah obat dapat berpenetrasi ke jaringan kulit dan memberikan efek terapeutik yang diharapkan (Verma, 2011)

Di masyarakat, penanganan demam pada anak secara tradisional dilakukan dengan menggunakan tanaman cocor bebek (Kalonchoe pinnata). Tanaman ini ditempel di dahi anak yang demam. Secara empiris tanaman ini sering digunakan untuk mengobati bisul, menurunkan demam, peluruh dahak, radang amandel, dan pengobatan luka bakar. Tanaman cocor bebek merupakan salah satu tanaman yang sering digunakan oleh masyarakat sebagai analgetic dan natipiretik dalam pengobatan secara turun temurun untuk mengobati demam, sakit kepala, radang sendi, reumatik dan berdasarkan hasil penelitian yang dilakukan tahun 2012 oleh Afzal et al., menyatakan bahwa pengobatan tradisional menggunakan daun cocor bebek di negaranegara Asia termasuk Indonesia, memiliki efek analgetic yang disebabkan oleh kandungan senyawa steroid dan flavonoid yang terkadung di dalam daun cocor bebek tersebut (Afzal, 2012. Tanko, 2012. Safitri, 2013).

Menurut penelitian Wijayanti (2009) menunjukkan bahwa pada dosis $4,5 \mathrm{ml} / \mathrm{kg}$ BB tikus, filtrat daun cocor bebek memiliki efek antipretik. Heni Purwitasari (2016) dalam penelitiannya menjelaskan bahwa ekstrak daun cocor bebek $50 \mathrm{mg}$ dan ekstrak daun tembelekan 720 mg merupakan kombinasi dosis yang paling efektif sebagai antipiretik. Selain itu telah diteliti efek analegetik dari tanaman cocor beber dalam penelitian Arrany Rahmaning Safitri (2013) menunjukkan bahwa dosis analgetic yang optimal dari infusa daun cocor bebek yang dapat menurunkan jumlah geliat lebih banyak dari mencit dibandingkan dengan kelompok control positif dan perlakuan lainnya dengan proteksi sebesar 76,32\%. Efek analgetik dari ekstrak etanol cocor bebek terhadap mencit juga telah diteliti Lara Amiyati (2015). Penelitian ini menunjukkan bahwa dosis efektif dalam menghambat jumlah geliat mencit adalah dosis $100 \mathrm{mg} / \mathrm{kgBB}(\mathrm{p}<0,05)$.

Beberapa efek farmakologi di atas dikarenakan adanya kandungan kimia yang terkandung dalam tanaman cocor bebek yaitu diantaranya alkaloid, fenol, flavonoid, saponin, tannin, triterpenoid, glikosida, karbohidrat, steroid dan asam amino (Matthew et al., 2013b).

Melihat efek farmakologi dari tanaman cocor bebek di atas, maka akan dibuat sebuah sediaan patch yang mengandung ekstrak cocor bebek untuk pengobatan demam. Polimer merupakan komponen utama dalam sediaan transdermal patch. Polimer menentukan dan mengontrol kecepatan pelepasan obat dari sediaan (Venkatalakshim. R, et all, 2012). Polimer yang digunakan sebagai pembawa ada dua jenis, yaitu polimer hidrofilik dan polimer hidrofobik (Rowe et al., 2009). Natrium CMC merupakan suatu polimer hidrofilik yang memiliki sifat dapat mengembang, sehingga akan mempengaruhi sifat fisik dari patch yang akan dibuat, berupa ketebalan, sifat organoleptis dan nantinya akan mempengaruhi proses kecepatan pelepasan zat aktif dari sediaan ke dalam kulit. Tujuan dari penelitian ini adalah membuat patch yang mengandung ekstrak tanaman cocor bebek dan menentukan mutu fisik sediaan patch yang mengandung ekstrak tanaman cocor bebek dengan variasi konsentrasi basis natrium $\mathrm{CMC}$.

\section{METODE}

\section{Jenis Dan Lokasi Penelitian}

Jenis penelitian ini adalah penelitian eksperimental laboratorium dengan memformulasikan ekstrak cocor bebek dalam bentuk sediaan pacth. Penelitian ini telah dilaksanakan pada bulan September 2019 Desember 2020 di Laboratorium Teknologi Farmasi Poltekkes Kemenkes Makassar.

\section{Populasi dan Sampel}

Sampel yang digunakan adalah tanaman cocor bebek yang diperoleh dari kota Makassar

\section{Alat dan Bahan Penelitian}

Alat-alat yang digunakan dalam penelitian ini adalah batang pengaduk, cawan porselin, gelas ukur $100 \mathrm{ml}$, kompor gas, sendok 
tanduk, timbangan analitik, erlenmeyer, cawan petri, beaker gelas, kaca arloji, pipet tetes, $\mathrm{pH}$ meter, aluminium foil, Pengaris. Sedangkan bahan yang digunakan dalam penelitian ini adalah tanaman cocor bebek, SCMC (Sodium Carbosimetilcelulosa), Gliserin, Propilen glikol Aquadest, Etanol 70\%, Etanol 96\%.

\section{Prosedur Kerja}

\section{Pembuatan Simplisia Cocor Bebek}

Tanaman cocor bebek dicuci sampai bersih, kemudian dibuat dalam potongan kecil. Potongan-potongan ini kemudian dikeringkan dengan cara dianginanginkan hingga kering.

\section{Pembuatan Ekstrak Cocor Bebek}

Simplisia cocor bebek diekstraksi dengan cara maserasi menggunakan pelarut etanol 96\% dengan cara merendam simplisia cocor bebek dengan pelarut etanol di dalam wadah maserasi. Perendaman dilakukan selama 3 x 24 jam sambil diaduk-aduk. Setelah 3 x 24 jam, hasil ekstraksi diserkai. Residu kemudian direndam kembali berulang-ulang hingga pelarut tidak berwarna lagi. Hasil perendaman dipekatkan dengan cara di rotavapor hingga diperoleh ekstrak pekat.

\section{Pembuatan Formulasi Pacth}

a. Rancangan Formula pacth, Tiap 20 gram formula mengandung

Tabel 1 : Rancangan formula pacth

\begin{tabular}{lccc}
\hline \multicolumn{1}{c}{ Bahan } & \multicolumn{3}{c}{ Bobot (gram) } \\
\cline { 2 - 4 } & F1 & F2 & F3 \\
\hline $\begin{array}{l}\text { Ekstrak Cocor } \\
\text { bebek }\end{array}$ & 1 & 1 & 1 \\
Sodium & 0,3 & 0,4 & 0,5 \\
Carboksimetil & & & \\
Celulosa & 0,12 & 0,12 & 0,12 \\
Gliserin & 0,04 & 0,04 & 0,04 \\
Propilenglikol & 10 & 10 & 10 \\
Aquadest & 8.54 & 8.44 & 8.34 \\
Etanol 70\% & & & \\
\hline
\end{tabular}

b. Pembuatan formulasi pacth

SCMC (Sodium Carboxymetil
Celulosa) ditimbang kemudian dilarutkan dalam 10 gram aquadest, lalu diaduk hingga homogen. Setelah terbentuk konsistensi gel dan homogen, ditambahkan propilenglikol dan gliserin, kemudian dihomogenkan. Dalam wadah terpisah ekstrak cocor beber dilarutkan dalam sejumlah etanol $70 \%$ (jumlah dalam formula), hingga ekstrak larut sempurna. Larutan ekstrak kemudian dimasukkan ke dalam basis patch dan dihomogenkan. Tahap selanjutnya bahan semua yang sudah homogen dituangkan ke cetakan sebanyak 20 gram, lalu dianginanginkan pada suhu ruangan selama beberapa hari sampai kering, Setelah kering maka formulasi pacth dapat dipisahkan dari cetakan, kemudian dilapisi dengan backing membran tegaderem sehingga menjadi pacth, kemudian disimpan dalam wadah kedap udara selama kurang lebih 7 hari kemudian sediaan patch dievaluasi.

\section{Evaluasi sediaan pacth}

a. Uji Organoleptis

Uji organoleptis meliputi pengamatan bau, bobot, warna dan bentuk, dari patch yang telah dibuat ( $\mathrm{R}$. Yogananda \& Bulugondla, 2012)

b. Keseragaman bobot

Keseragaman bobot dihitung dengan cara menimbang 10 buah patch yang diambil secara random dari setiap seri, kemudian dihitung bobot rata-ratanya.

\section{c. Uji Ketebalan}

Setiap patch diukur ketebalan sisinya menggunakan menggunakan mistar atau mikrometer sekrup. Pengukuran ini dilakukan sebanyak tiga kali.

d. Persentase Kehilangan Air

Kehilangan air pada sediaan patch ditentukan dengan cara menimbang awal patch setelah dibuat sebagai 
bobot awal, kemudian sediaan disimpan pada suhu ruangan selama 7 hari. Selama penyimpanan, sediaan ditimbang setiap hari hingga hari ke 7 (sebagai data). Setelah disimpan, pada hari ke 7, kemudian ditimbang sebagai bobot akhir. Persentase kehilangan air dapat dihitung dengan menggunakan rumus:

$$
\begin{aligned}
& \text { Persentase Kehilangan } \\
& =\frac{\text { bobot awal }- \text { bobot akhir }}{\text { bobot akhir }} \times 100 \%
\end{aligned}
$$

\section{e. Uji pH}

Diambil patch secara random, kemudian didispersikan dalam sejumlah aquadest, diaduk hingga homogen. Setelah homogen, $\mathrm{pH}$ diukur dengan menggunakan kertas $\mathrm{pH}$ universal (R. Yogananda \& Bulugondla, 2012).

f. Uji daya tahan lipatan (Folding Endurance)

Pengujian dilakukan dengan cara melipat patch secara berulang-ulang hingga maksimal 300 kali pada tempat yang sama atau pada posisi lipatan yang sama. Jika tidak memberikan hasil patah, maka sediaan mempunyai nilai daya tahan lipatan ( $\underline{\text { R. Yogananda }}$ $\underline{\text { \& Bulugondla, 2012). }}$.

\section{HASIL}

\section{Rendamen Ekstrak}

Dari hasil penelitian diperoleh rendamen ekstrak sebagai berikut

Tabel 2. Rendamen Ekstrak Etanol Cocor Bebek

\begin{tabular}{ccc}
\hline Berat simplisia Kering (g) & Berat Ekstrak (g) & $\begin{array}{c}\text { Rendamen Ekstrak } \\
\text { Daun (\%) }\end{array}$ \\
\hline 135.66 & 36.7 & 27.05 \\
\hline
\end{tabular}

Sumber : Data Primer 2020

\section{Uji Organoleptis}

Tabel 3. Uji Organoleptis Sediaan Patch

\begin{tabular}{lccc}
\hline \multicolumn{1}{c}{ Uji Organoleptis } & F1 & F2 & F3 \\
\hline Warna & Hijau Muda & Hijau Muda & Hijau Muda \\
Bau & Ekstrak & Ekstrak & Ekstrak \\
Bentuk & Gel transparan & Gel transparan & Gel transparan \\
Homogenitas & Tidak Homogen & Homogen & Homogen \\
\hline
\end{tabular}

Sumber : Data Primer 2020

\section{Uji Evaluasi Fisik}

Tabel 4. Uji Evaluasi Fisik Sediaan Patch

\begin{tabular}{lccc}
\hline \multicolumn{1}{c}{ Pengujian } & F1 & F2 & F3 \\
\hline Keseragaman Bobot $(\mathrm{g})$ & 5.56 & 6.26 & 6.60 \\
Ketebalan $(\mathrm{cm})$ & 0.10 & 0.17 & 0.23 \\
Presentasi Kehilangan Air & 8.07 & 5.94 & 2.75 \\
pH & 6 & 6 & 6 \\
Daya tahan lipatan & $<300$ & $>300$ & $>300$ \\
\hline
\end{tabular}

Sumber : Data Primer 2020

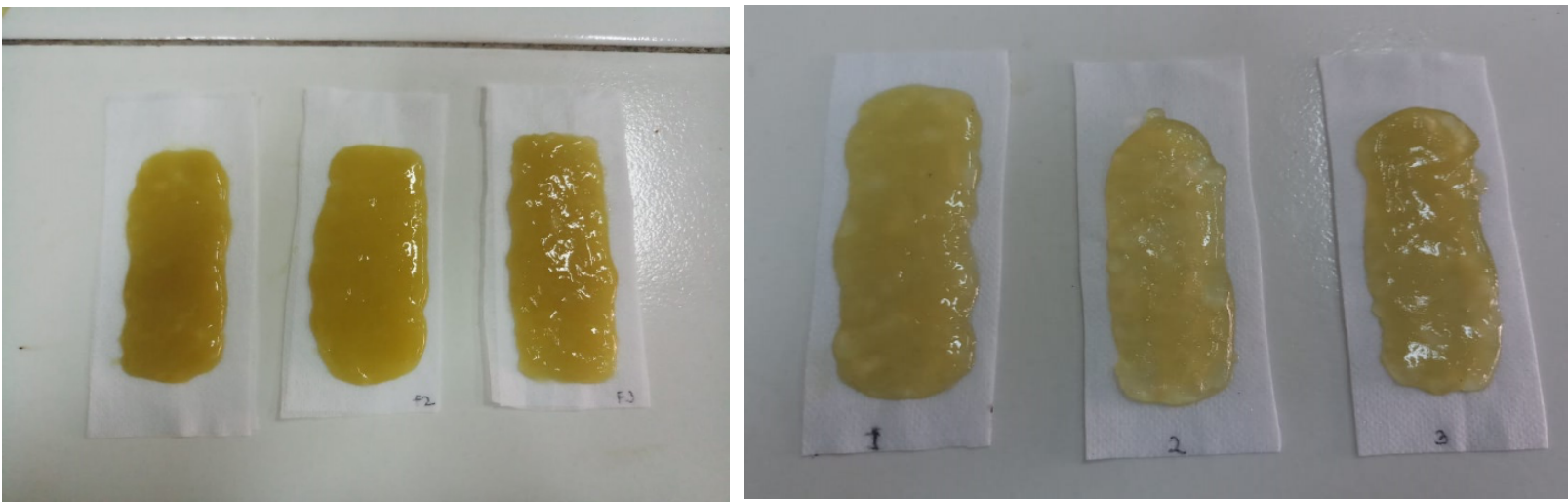

Gambar 1. Formula Sediaan Patch 


\section{PEMBAHASAN}

Tanaman cocor bebek telah dikenal di masyarakat dan telah secara turun temurun digunakan sebagai obat. Salah satunya adalah penurun demam terutama bagi anak balita. Penggunaannya pun sederhana, dimana daun cocor bebek ditumbuk, kemudian ditempelkan di dahi. Tanaman ini memberikan efek sensasi dingin di kepala, sehingga memberikan kesejukan bagi pasien. Hal ini didukung oleh beberapa penelitian yang menjelaskan bahwa tanaman ini mengandung senyawa yang mempunyai efek analgetic dan antipiretik. Efek dingin juga dihasilkan oleh kandungan air di helaian daun cocor bebek (Biswas SK, et al, 2011)

Untuk mendapatkan zat aktif yang terkandung, dilakukan dengan cara mengekstraksi tanaman tersebut. Metode yang dipilih adalah metode maserasi. Dimana metode ini merupakan metode dingin, dimana tidak menggunakan pemanasan sehingga kestabilan zat aktif tetap terjaga.

Komponen utama pada sediaan patch adalah polimer. Polimer mengontrol laju pelepasan obat dari reservoir obat di patch transdermal. Salah satu polimer yang digunakan adalah natrium $\mathrm{CMC}$. $\mathrm{Na} \mathrm{CMC}$ ini mudah terdispersi dalam air dingin maupun air panas.

Propilenglikol meningkatkan pergerakan molekul air di dalam matriks. Menurut pada derajat kelarutan airnya, dimana semakin banyak plasticizer yang larut dalam air (propylene glycol) akan membuat saluran yang memungkinkan penetrasi yang lebih cepat dari media disolusi ke matriks polimer, juga plasticizer dengan berat molekul lebih rendah (propilen glikol) lebih banyak molekul per satuan berat dibandingkan dengan plasticizer dengan berat molekul tinggi. Ini molekul dapat lebih mudah menembus antara rantai polimer dari zat pembentuk film dan dapat berinteraksi dengan gugus fungsi tertentu dari polimer (Nawal, 2001)

Dari uji organoleptis diperoleh data bahwa ketiga formula memiliki warna yang sama yaitu hijau, yang merupakan warna dari ekstrak. Bau dan bentuk juga sama yaitu berbau ekstrak dan berbentuk gel transparan. Formula 1 memiliki penampakan yang tidak homogen, sedangkan formula II dan dan III, homogen. Ketidakhomogen ini, disebabkan karena proses pengadukan yang tidak sempurna, karena natrium cmc sewaktu didispersikan dalam air, membentuk gelembung-gelembung udara.

Dari pengujian bobot dan ketebalan, diperoleh data dimana terjadi peningkatan bobot dan ketebalan sesuai dengan penambahan konsentrasi polimer natrium CMC. Semakin banyak konsentrasi natrium CMC, maka konsistensi dari patch akan semakin kental, sehingga membuat sediaan makin berat dan tebal. (Puspitasari, K.D, 2016). Dari pengujian bobot dan ketebalan diperoleh juga data bahwa kedua pengukuran ini berada dalam rentang nilai yang seragam. Keseragaman nilai bobot dan ketebalan menunjukkan pula distribusi zat aktif yang seragam pula. Hal ini didukung pula karena pada proses pembuatan patch, zat aktif didispersikan terlebih dahulu dalam pelarut etanol.

Salah satu factor yang perlu ditinjau juga dalam pembuatan sediaan patch adalah factor ketebalan patch. Semakin ringan patch, maka akan semakin nyaman digunakan oleh pengguna khususnya anak-anak karena jika ringan, maka si pengguna serasa tidak menggunakan apa-apa. Ringan atau beratnya sebuah patch tergantung dari ketebalan patch, dan ketebalan patch meningkat berbanding lurus dengan peningkatan berat matriks, dalam hal ini penambahan bahan natrium CMC. Peningkatan berat ini disebabkan karena mengembangnya struktur ikatan rantai polimer dari natrium CMC yang diakibatkan oleh tertahan dan terjebaknya pembawa air dalam rongga polimer tersebut (Rowe et al., 2009).. Makin banyak natrium CMC, maka banyak pula air yang teretensi, sehingga makin mengembang dan makin berat. (Kurniawati, 2016). Sediaan matriks patch yang terlalu tebal akan mempersulit lepasnya zat aktif dari patch (Arifin et al., 2019). Hal ini terlihat dari peningkatan bobot secara berurutan pada formula 1,2 dan 3 .

Pengukuran $\mathrm{pH}$ dilakukan dengan tujuan menentukan $\mathrm{pH}$ dari sediaan apakah sesuai dengan $\mathrm{pH}$ tempat bekerjanya sediaan. Sedapat mungkin, $\mathrm{pH}$ sebuah sediaan harus sama dengan $\mathrm{pH}$ kompartemen dari tempat kerja. Hal ini disebabkan agar sediaan tersebut tidak menimbulkan efek iritasi pada tempat kerja, serta yang paling penting, agar zat aktif tersebut dapat terjaga kestabilannya dan dapat bekerja dengan baik di side effect tersebut, karena $\mathrm{pH}$ merupakan salah satu factor yang dapat mempengaruhi sifat dari suatu molekul obat. Dari hasil penelitian, diperoleh $\mathrm{pH}$ sediaan patch untuk semua formula yaitu 6. Hal ini telah sesuai dengan $\mathrm{pH}$ kulit yaitu 6-7 sebagai side effectnya, sehingga tidak akan menghasilkan efek iritasi.

Pengukuran kadar air tertinggi secara berturut-turut dari tertinggi ke rendah yaitu formula F3, F2 dan F1. Tingginya kadar air pada formula F3, karena pada formula ini mengandung natrium CMC dengan konsentrasi yang paling tinggi dibanding F2 dn F1. Seperti dijelaskan pada paragraph sebelumnya bahwa 
makin banyak natrium CMC maka makin banyak kadar air yang akan tertahan dalam matriks polimernya. Hal ini juga juga didukung oleh sifat natrium $\mathrm{CMC}$ yang bersifat polimer golongan anionic yang memiliki kemampuan menarik air (R. Yogananda dan Rakesh, 2012).

Kadar air juga mengacu kepada factor kelembaban sediaan. Kelembaban suatu sediaan akan dapat mempengaruhi kestabilan sebuah sediaan farmasi (Kumar et al., 2013). Makin tinggi kadar air, maka makin lembab sediaan tersebut. Kelembaban pada suatu sediaan patch yang terlalu rendah dapat menyebabkan patch tersebut mudah rusak dan patah karena rapuh. Sedangkan jika kelembaban sediaan terlalu tinggi maka akan berpengaruh pada penyimpanan yang mudah rusak akibat mudah ditumbuhi oleh bakteri dan jamur, (Mukherjee et al., 2005), dimana hal ini disebabkan karena air merupakan media pertumbuhan yang baik bagi bakteri dan jamur.

Pengujian selanjutnya adalah daya tahan lipatan pada sediaan dimana sediaan dilipat berulang-ulang kali sebanyak minimal 100 kali hingga maksimal 300 kali pada tempat yang sama. Jumlah pelipatan menunjukkan nilai ketahanan matriks terhadap pelipatan sampai patah (Pudyastuti et al., 2014). Sediaan patch memenuhi kategori baik jika mempunyai nilai ketahanan lipat lebih dari 300 kali (Jhawat et al., 2013). Pada penelitian ini menunjukkan hasil dimana tidak terdapat kerusakan hingga pelipatan ke 300. Adanya tambahan gliserin sebagai plasticizer berinteraksi dengan polimer meningkatkan fleksibilitas secara molecular dari polimer (Stukalin, 2010) dengan cara gliserin membentuk lapisan elastis polimer sehingga tidak mudah sobek. Semakin elastis suatu polimer, maka akan semakin tahan terhadap lipatan.

\section{KESIMPULAN}

Dari penelitian ini, dapat ditarik

kesimpulan yaitu :

1. Ekstrak tanaman cocor bebek dapat dibuat dalam bentuk patch

2. Formula II menghasilkan mutu fisik sediaan patch yang paling baik dibanding formula I dan Formula III.

\section{SARAN}

Setelah melakukan formulasi dan menguji kestabilan fisik formulanya, diharapkan selanjutnya untuk diadakan uji efektivitas secara in vitro.

\section{DAFTAR PUSTAKA}

Afzal M, Gupta G, Kazmi I, Rahman M, Afzal O, Alam J, et al. Antiinflamatory and analgesic potential of A novel from Bryophyllum pinnatum. 2012; Elsevier Journal Fitoterapia 83:853-858.

Arifin, A., Sartini dan Martianti. (2019). Evaluasi Karakteristik Fisik dan Uji Permeasi pada Formula Patch Aspirin menggunakan Kombinasi Etil Selulosa dengan Polivinilpirolidon. Jurnal Sains dan Kesehatan, 2(1), pp. 40-49.

Amiyati, L, 2015, Uji Aktivitas Analgetik Ekstrak Etanol Daun Cocor Bebek (Kalanchoe pinnata (Lam.) Pers.) terhadap Mencit (Mus musculus) Jantan Galur Swiss, (Skripsi), Pontianak Fakultas Kedokteran

Biswas SK, et al, 2011, Literature review on pharmacological potentials of Kalanchoe pinnata (Crassulaceae), Review, African Journal of Pharmacy and Pharmacology Vol. 5(10), pp. 1258-1262, Bangladesh

Jhawat, Saini, Kamboj dan Maggon. (2013). Transdermal Drug Delivery System: Approaches and Advancements in Drug Absorption Through Skin. International Journal of Pharmaceutical Sciences Review and Research, 20 (1), pp. 47-56

Kumar, S.V., Turun, P. dan Kumar T.A. (2013). Transdermal drug delivery system for nonsteroidal anti-inflammatory drugs: A review, Indo American Journal of Pharmaceutical Research, 3(5), pp. 3588-3605.

Matthew S, Khosla KK, Matthew C, Bhowmik D. Preliminary phytochemical studies of Kalanchoe pinnata(Lam.) Pers. $J$ Med Plants Stud, 2013b; 1: 19-23.

Mukherjee, B., Kanupriya, M.S., Das, S. dan Patra B. (2005). Sorbitan monolaurate 20 as a potential skin permeation enhancer in transdermal patches. The Journal of Applied Research, 5(1), pp. 96-108.

Nawal A. Rijab. Preparation and evaluation of fentanyl transdermal patches using lidocaine as a model drug and azelaic acid as a penetration enhancer. Ph.D. Thesis, Faculty of PharmacyUniversity of Baghdad 2010 
Pudyastuti, B., Nugroho, A.K. dan Martono, S. (2014). Formulasi Matriks Transdermal Pentagamavunon-0 dengan Kombinasi Polimer PVP K30 dan Hidroksipropil Metilselulosa, Jurnal Farmasi Sains Dan Komunitas, 11(2), pp. 44-49.

Puspitasari, K.D., Nurahmanto, D. dan Ameliana, L. (2016). Optimasi Hidroksipropil Metilselulosa dan Carbopol terhadap Moisture Content dan Laju Pelepasan Patch Ibuprofen In Vitro. e-Jurnal Pustaka Kesehatan, 4 (2), pp.229-234.

Purwitasari, H., Yuliet, Ihwan, 2017, Efek Antipiretik Kombinasi Ekstrak Daun Cocor Bebek (Kalanchoe pinnata L.) Dan Ekstrak Daun Tembelekan (Lantana camara L.) Pers. terhadap Marmut (Cavia porcellus) dengan Demam yang Diinduksi Pepton, GALENIKA Journal of Pharmacy Vol. 3 (1) : 43 - 48, Palu

R. Yoganda \& Bulugondla, Rakesh. 2012. An overview on mucoadhesif buccal pacthes. Int J Universal Pharm and Life Sci. Hal : 360-384.

Rowe, R.C. et Al. (2009). Handbook Of Pharmaceutical Excipients, 6th Ed, The Pharmaceutical Press, London

Safitri AR. 2013. Uji efek analgetik infusa daun cocor bebek (Kalanchoe pinnata (Lam.) Pers.) terhadap mencit jantan galur Swiss yang diinduksi dengan asam asetat [Skripsi]. Pontianak Fakultas Kedokteran.

Stukalin EB, Douglas JF and Freed KF, 2010. Plasticization and antiplasticization of polymer melts diluted by low molar mass species. The Journal of Chemical physics Feb; Vol. 132 (Issue 8):084504.

Tanko Y, Mohammed A, Saleh MIA, Etta E, Bakp IG, Yerima M. 2012 Antinociceptive and anti-inflamatory activities of etanol extract of Bryophyllum Pinnatum laboratory animals.; IOSR Journal of Dental and Medical Sciences (JDMS) 3:46.

Tortora, J. G. 1990. Principles of Anatomy and Physiology. Edisi Keenam, Harper\& Row Publisher, New York.

Venkatalakshim. R, Sudhakar, Yajaman, Chetty.C, Madhuchudan, sasikala.C \& Varma.M, Mohan. 2012. Buccal drug delivery system using adhesive polimeric pacthes. Int J Pharm Scie and Res. Vol.3. Hal :38.

Verma, Surender, Kaul, Mahima, Aruna, Rawat \& Saini, Sapna. 2011. An overview on buccal drung delivery system. Int $\mathrm{J}$ Pharm Sci and Res. Vol. 2 (6). Hal : $1304-13$

Wijayanti, Y, 2009. Pengaruh Berbagai Dosis Filtrat Daun Cocor Bebek Terhadap Penurunan Suhu Tubuh Tikus Putih Hiperterimia, Repisatory Universitas Muhammadiyah Malang.

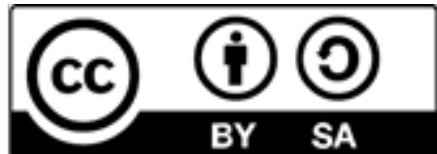

